Pesq. Vet. Bras. 26(1):14-20, jan./mar. 2006

\title{
Forma nervosa de listeriose em caprinos ${ }^{1}$
}

\author{
Daniel R. Rissi², Raquel R. Rech ${ }^{2}$, Ricardo R. Barros², Glaucia D. Kommers ${ }^{3}$, \\ Ingeborg M. Langohr ${ }^{4}$, Felipe Pierezan ${ }^{3}$ e Claudio S.L. Barros ${ }^{3 *}$
}

\begin{abstract}
Rissi D.R., Rech R.R., Barros R.R., Kommers G.D., Langohr I.M., Pierezan F. \& Barros C.S.L. 2006. [Listeric meningoencephalitis in goats.] Forma nervosa de listeriose em caprinos. Pesquisa Veterinária Brasileira 26(1):14-20. Departamento de Patologia, Universidade Federal de Santa Maria, 97105-900, Santa Maria, RS, Brazil.E-mail: claudioslbarros@uol.com.br

A neurologic disease was observed in three young adult goats (indentified as A-C) from a herd of 100 goats during October-December, 2004. Clinical signs included head tilt, torticollis, nystagmus, staggering, falls and eventually recumbency and paddling, with stiff limbs. Treatment of Goat $\mathrm{C}$ with antibiotics resulted in a temporary remission of the clinical signs. The clinical courses where 5,10 and 30 days respectively for Goats A, B and C. Goat A died spontaneously and the other two where euthanatized in extremis. No gross changes were observed. Histologic lesions were predominantly unilateral, with inflammatory and degenerative changes, extending from the medulla oblongata to the thalamus. In all 3 cases there were perivascular cuffings of one or more types of mononuclear cells (lymphocytes, plasma cells, activated macrophages) and occasionally neutrophils associated with areas of malacia where Gitter cells filled spaces of parenchymal loss. Additionally, Goat B had microabscesses in the medulla, pons, and mesencephalon and multifocal neutrophilic and lymphocytic infiltrates within the fascicles of the trigeminal nerve and in the cerebellar leptomeninges. In the brainstem of Goat $\mathrm{C}$, there was multifocal granulomatous inflammation which included epithelioid macrophages and occasional multinucleated giant cells. Listeria sp antigen was detected by imunohistochemistry in routinely processed sections of mesencephalon from Goats A and C and of pons from Goat B.
\end{abstract}

INDEX TERMS: Listeria sp, Listeria monocytogenes, listeriosis, encephalitis, immunohistochemistry, pathology, diseases of goats.

RESUMO.- Em um rebanho de 100 caprinos, foram observados casos de uma doença neurológica em três animais adultos jovens (identificados como A-C) entre outubro e dezembro de 2004. Os sinais clínicos incluíam desvio da cabeça, torcicolo, nistagmo, andar desequilibrado e quedas que acabavam em decúbito, durante o qual o caprino executava movimentos de pedalagem com os membros rígidos. Tratamento com antibióticos no Caprino $C$ resultou em remissão temporária dos sinais. A evolução clínica foi de 5, 10 e 30 dias, respectivamente, para os Caprinos A, B e C. O Caprino A morreu espontaneamente e

\footnotetext{
${ }^{1}$ Recebido em 5 de abril de 2005.

Aceito para publicação em 31 de agosto de 2005.

${ }^{2}$ Programa de Pós-Graduação em Medicina Veterinária, área de concentração em Patologia Veterinária, Universidade Federal de Santa Maria (UFSM).

${ }^{3}$ Depto Patologia, UFSM, 97105-900, Santa Maria, Rio Grande do Sul. *Autor para correspondência. E-mail. claudioslbarros@uol.com.br

${ }^{4}$ Animal Disease Diagnostic Laboratory, Purdue University, 406 South University, West Lafayette, IN 47907, Estados Unidos.
}

os outros dois foram eutanasiados na fase terminal da doença. Não foram observadas alterações macroscópicas. Lesões histológicas eram predominantemente unilaterais e consistiam de alterações inflamatórias e degenerativas que se estendiam do bulbo ao tálamo. Em todos os casos havia manguitos perivasculares de um ou mais tipos de células mononucleares (linfócitos, plasmócitos, macrófagos ativados) e ocasionalmente neutrófilos associados a áreas de malacia onde células Gitter preenchiam os espaços de perda do parênquima. Adicionalmente, o Caprino B tinha microabscessos no bulbo, ponte, e mesencéfalo e infiltrado neutrofílico e linfocítico multifocal nos fascículos do nervo trigêmeo, próximo ao gânglio de Gasser, e nas leptomeninges do cerebelo. No tronco encefálico do Caprino $\mathrm{C}$, a reação era multifocal e com característica granulomatosa e incluía células epitelióides e, ocasionalmente, células gigantes multinucleadas. Listeria sp foi detectada por imunoistoquímica em cortes de mesencéfalo rotineiramente processado dos Caprinos A e C e de ponte do Caprino B.

TERMOS DE INDEXAÇÃO: Listeria sp, Listeria monocytogenes, listeriose, encefalite, imunoistoquímica, patologia, doenças de caprinos. 


\section{INTRODUÇÃO}

Listeriose é uma enfermidade infecciosa causada pelas bactérias Gram-positivas, Listeria spp. Afeta várias espécies animais, induzindo três formas de manifestação clínica: (1) septicemia com abscessos em vísceras como fígado e baço, (2) aborto e (3) doença neurológica (meningoencefalite). Geralmente, em um surto, observa-se apenas uma dessas três formas. A forma septicêmica afeta especialmente ruminantes, suínos, coelhos e aves recémnascidos. Listeria monocytogenes é causa de aborto, principalmente em ovinos e bovinos, e de doença neurológica, principalmente em ovinos, caprinos e bovinos (Schneider 1994, Summers et al. 1995, George 2002). L. ivanovii causa aborto em ruminantes (Schneider 1994). Doença neurológica é mais comum em regiões de clima temperado, onde os casos ocorrem principalmente no inverno e início da primavera (Schneider 1994); silagem de má qualidade ( $\mathrm{pH}$ acima de 5,5) favorece o crescimento da bactéria (Summers et al. 1995, George 2002). Outras fontes de infecção incluem solo e alimentos contaminados e fezes ou leite de animais portadores (Schneider 1994).

Em ruminantes, a forma nervosa é causada por $L$. monocytogenes e ocorre esporadicamente ou em surtos, com morbidade baixa e letalidade alta, geralmente associados à alimentação com silagem (Løken \& Grønstø 1982, Jubb \& Huxtable 1993, Schneider 1994). A doença encefálica em bovinos pode ser subaguda, mas em ovinos e cabras é geralmente aguda e fatal (Lippman 1969).

Lesões macroscópicas não são comuns, mas pode ser observada hiperemia das leptomeninges e turvamento do líquido cefalorraquidiano; ocasionalmente, em cortes transversais do tronco encefálico, observam-se focos de malacia castanho-amarelados (Summers et al. 1995). As alterações microscópicas consistem de microabscessos, manguitos mononucleares nos espaços de Virchow-Robin, degeneração axonal e presença de células Gitter. Essas lesões distribuem-se de modo assimétrico, principalmente no bulbo e na ponte, mas podem ocorrer em qualquer local do tronco encefálico, desde o tálamo até a medula espinhal cervical (Asahi et al. 1957, Charlton \& Garcia 1977).

O diagnóstico pode ser confirmado pela cultura, deteç̧ão do microrganismo em colorações especiais (Gram), na imunofluorescência ou imunoistoquímica - IHQ (Peixoto 1986, Marco et al. 1988, Johnson et al. 1995, Campero et al. 2002, Loeb 2004), ou pela técnica de reação em cadeia de polimerase - PCR (Batt 1999).

Apesar de relatos de casos esporádicos da forma nervosa de listeriose em ruminantes no Brasil (Sanches et al. 2000, Schild 2001, Schwab et al. 2004), são escassos os relatos detalhados da enfermidade no país. Neste trabalho são descritos três casos de listeriose em caprinos com evolução clínica e lesões subagudas e crônicas, pouco comuns. A confirmação do diagnóstico por IHQ e os aspectos epidemiológicos, clínicos e patológicos desses casos são discutidos.

\section{MATERIAL E MÉTODOS}

Dados epidemiológicos e clínicos foram obtidos junto ao proprietário e aos clínicos que atenderam os casos. Os caprinos foram identificados por letras A-C conforme a sequiência em que ocorriam. Um caprino (A) teve morte espontânea e dois foram sacrificados in extremis. Os três foram necropsiados. Fragmentos de várias vísceras foram colhidos e fixados em formol a $10 \%$. Os encéfalos foram colhidos inteiros e fixados por quatro ou cinco dias. $\mathrm{O}$ exame macroscópico do encéfalo foi então procedido em seções coronais feitas em intervalos de $0,5 \mathrm{~cm}$. Para histopatologia, foram selecionados os seguintes cortes do encéfalo: 1) bulbo na altura do óbex, 2) cerebelo, 3) ponte na altura dos pedúnculos cerebelares, 4) mesencéfalo, na altura dos colículos rostrais, 5) lobo telencefálico occipital, 6) córtex parietal, hipocampo e tálamo subjacentes, na altura dos corpos mamilares, e 7) lobo telencefálico frontal e núcleos basais subjacentes. Para cada caso também foram colhidos blocos de tecidos contendo a rete mirabile carotídea, hipófise e gânglio do trigêmeo e outros órgãos como fígado, rim, pulmão, olho e coração. O material foi processado rotineiramente para histologia e corado com hematoxilina e eosina (HE). Seções do mesencéfalo dos casos $\mathrm{A}$ e $\mathrm{C}$ e da ponte do caso $\mathrm{B}$ foram submetidas à coloração de Brown \& Brenn para tecidos e à coloração de $\mathrm{IHQ}$, segundo procedimentos estabelecidos anteriormente (Ramos-Vara \& Beissenherz 2000). Foi utilizado como anticorpo primário um anticorpo policlonal antiantígeno celular $(\mathrm{O})$ de Listeria spp na diluição de 1:1000. Fragmentos de tecido emblocados em parafina foram submetidos à técnica de reação em cadeia da polimerase (PCR) para amplificação do DNA de Listeria monocytogenes ${ }^{5}$.

\section{RESULTADOS}

Os casos ocorreram em 3 caprinos jovens adultos (15-18 meses de idade) de uma propriedade rural do município de Ivorá, região central do Rio Grande do Sul, no período de outubro a dezembro de 2004 . Na propriedade havia 100 caprinos distribuídos nas seguintes categorias: dois machos adultos, 28 fêmeas acima de 12 meses de idade e 70 caprinos (machos castrados e fềmeas) entre 3 e 7 meses de idade. Os caprinos são explorados para produção de carne e mantidos em um piquete de 8 ha onde tinham contato direto com galinhas e suínos. Havia bovinos num piquete ao lado e contato desses animais com os caprinos através da cerca era possível. As galinhas geralmente se alimentavam e defecavam no cocho onde era colocada a ração para os caprinos. A ração, feita na propriedade, consistia de farelo de soja, trigo, milho e arroz feitos na propriedade. No inverno de 2004, os caprinos haviam recebido silagem de milho.

Os sinais relatados nos três casos foram semelhantes e incluíam anorexia, desvio da cabeça, torcicolo (Fig.1), andar instável e quedas. Nas fases finais da doença os caprinos assumiam decúbito lateral, realizando movimentos de pedalagem com os membros rígidos. Os Caprinos A e C foram tratados com antibióticos. O Caprino A não apresentou resposta ao tratamento, entretanto, o Caprino $C$ teve remissão dos sinais clínicos nos primeiros 5 dias, mas os sinais recrudesceram cerca de um mês após o início da doença.

Não foram encontradas lesões de necropsia relacionadas à doença. Os principais achados histopatológicos estão resumidos no Quadro 1. As lesões localizavam-se no tronco encefálico e eram preferencialmente unilaterais. Lesões mais agudas foram observadas no Caprino B e caracterizavam-se por alterações degenerativas associadas a microabscessos (Fig.2) e infiltrado

\footnotetext{
5 Teste realizado no Animal Disease Diagnostic Laboratory, Purdue University, 406 South University, West Lafayette, IN 47907, Estados Unidos.
} 

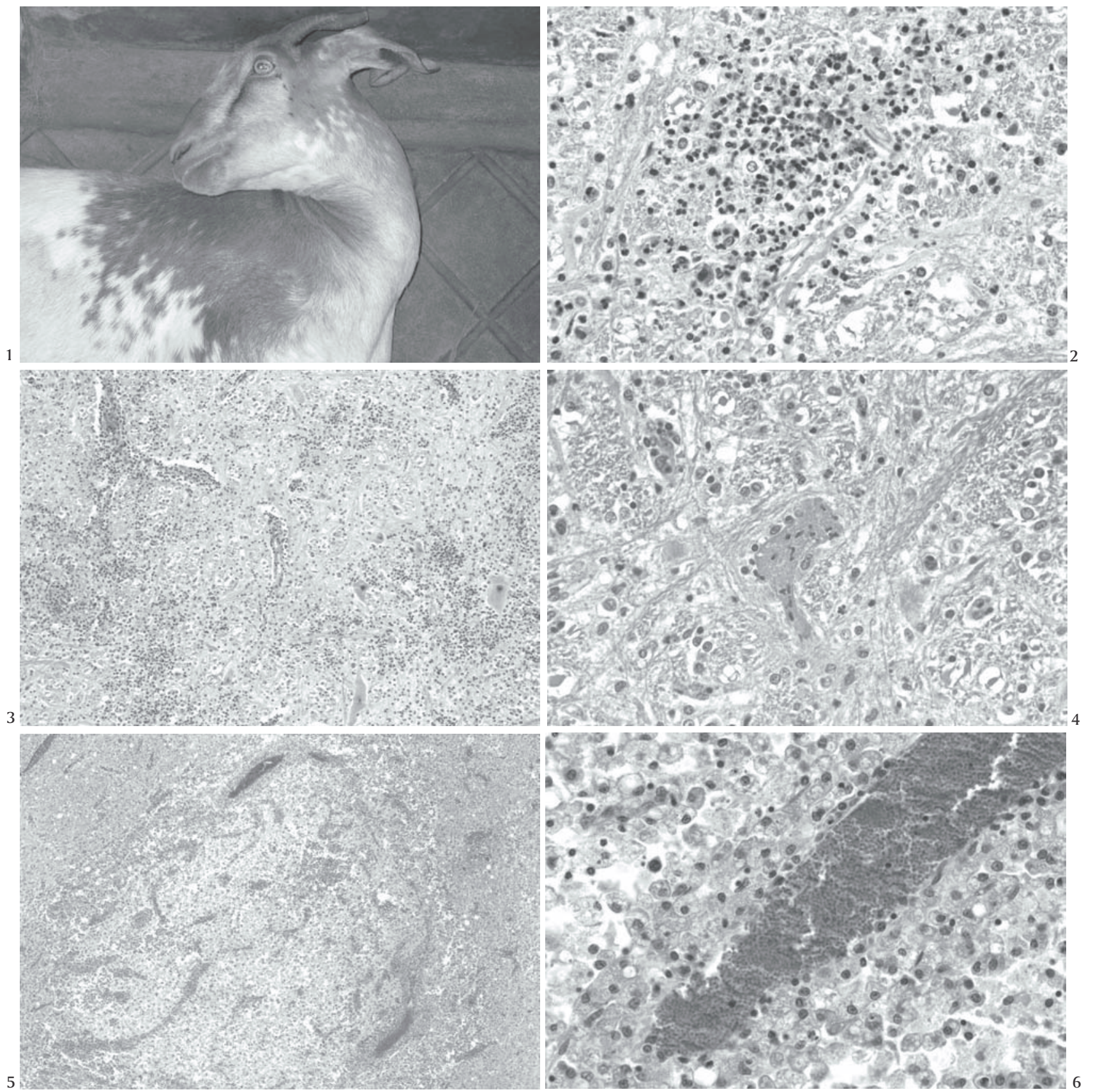

Fig.1. Caprino C, com listeriose, apresentando desvio da cabeça e torcicolo.

Fig.3. Infiltrado neutrofílico difuso na neurópila da ponte do Caprino B com listeriose. HE, obj.10.

Fig.5. Foco unilateral de malacia na ponte, na altura dos pedúnculos cerebelares, do Caprino A com listeriose. HE, obj.4.

neutrofílico difuso na neurópila (Fig.3). Manguitos perivasculares constituídos por 2-5 camadas de linfócitos, esferóides axonais, neuronofagia (Fig.4) e infiltrado misto nas leptomeninges com-

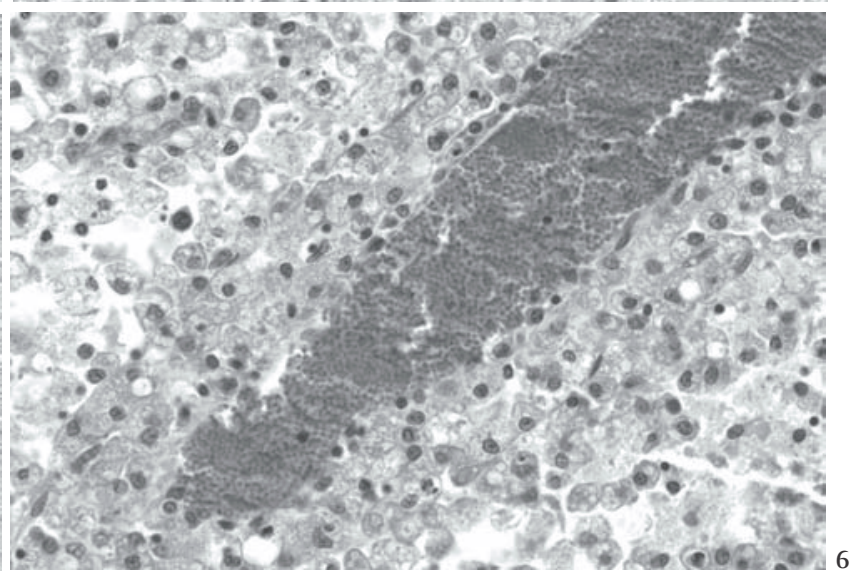

Fig.2. Microabscesso no bulbo do Caprino B com listeriose. HE, obj.40.

Fig.4. Células inflamatórias, principalmente neutrófilos, fagocitam fragmentos do citoplasma de um neurônio morto (neuroniofagia) na ponte do Caprino B com listeriose. HE, obj. 40.

Fig.6. Extenso manguito perivascular constituído por plasmócitos, linfócitos e células Gitter na ponte do Caprino A com listeriose. HE, obj.40.

pletavam o quadro. Lesões com idade intermediária foram observadas no Caprino A e eram caracterizadas por focos unilaterais de malacia (Fig.5), manguitos perivasculares linfoistioplas- 
Quadro 1. Dados sobre os três casos de listeriose em caprinos

\begin{tabular}{|c|c|c|c|c|c|c|}
\hline \multirow[t]{2}{*}{ Caprino } & \multirow[t]{2}{*}{ Idade } & \multirow[t]{2}{*}{ Sexo } & \multirow[t]{2}{*}{ Raça } & \multirow{2}{*}{$\begin{array}{l}\text { Evolução dos } \\
\text { sinais clínicos }\end{array}$} & \multicolumn{2}{|r|}{ Alterações histopatológicas } \\
\hline & & & & & Distribuição & Tipo \\
\hline \multirow[t]{5}{*}{ A } & 15 meses & $\mathrm{F}^{\mathrm{a}}$ & Boer & 5 dias & Bulbo & $\begin{array}{l}\text { Manguitos perivasculares linfoplasmocitários moderados, edema } \\
\text { difuso moderado, gliose difusa e esferóides axonais }\end{array}$ \\
\hline & & & & & $\begin{array}{l}\text { Ponte na altura } \\
\text { dos pedúnculos } \\
\text { cerebelares }\end{array}$ & $\begin{array}{l}\text { Manguitos linfoplasmocitários. Foco de malacia unilateral com cé- } \\
\text { lulas Gitter, degeneração neuronal, esferóides axonais e neutrófilos } \\
\text { na neurópila }\end{array}$ \\
\hline & & & & & $\begin{array}{l}\text { Mesencéfalo, pró- } \\
\text { ximo ao núcleo } \\
\text { vermelho }\end{array}$ & $\begin{array}{l}\text { Manguitos perivasculares linfoistioplasmocitários acentuados, área } \\
\text { focal unilateral de malacia com células Gitter e áreas de desmieliniza- } \\
\text { ção, meningite linfoplasmocitária discreta }\end{array}$ \\
\hline & & & & & Tálamo & $\begin{array}{l}\text { Manguitos perivasculares linfoplasmocitários focais, tumefação } \\
\text { endotelial, esferóides axonais e áreas de malacia predominantemen- } \\
\text { te unilaterais com células Gitter }\end{array}$ \\
\hline & & & & & Cerebelo & $\begin{array}{l}\text { Manguitos perivasculares linfoplasmocitários e edema difuso mode- } \\
\text { rado na substância branca }\end{array}$ \\
\hline \multirow[t]{2}{*}{ B } & 17 meses & $M^{b}$ & Mista & 10 dias & $\begin{array}{l}\text { Bulbo, ponte } \\
\text { e mesencéfalo }\end{array}$ & $\begin{array}{l}\text { Manguitos perivasculares acentuados constituídos por } 2-5 \text { camadas } \\
\text { de linfócitos, tumefação endotelial, neutrófilos difusos na neurópila } \\
\text { e microabscessos predominantemente unilaterais, degeneração } \\
\text { neuronal, neuronofagia e esferóides axonais }\end{array}$ \\
\hline & & & & & $\begin{array}{l}\text { Cerebelo } \\
\text { Nervo trigêmeo }\end{array}$ & $\begin{array}{l}\text { Discreto infiltrado linfocitário e neutrofílico na leptomeninge. } \\
\text { Infiltrado misto (neutrófilos e linfócitos) multifocal unilateral }\end{array}$ \\
\hline \multirow[t]{2}{*}{$\mathrm{C}$} & 18 meses & M & Boer & 30 dias & $\begin{array}{l}\text { Bulbo, ponte } \\
\text { e mesencéfalo }\end{array}$ & $\begin{array}{l}\text { Infiltrado perivascular multifocal, linfoistioplasmocitário com ma- } \\
\text { crófagos epitelióides e células gigantes (predominantemente unila- } \\
\text { teral no bulbo e ponte, unilateral no mesencéfalo). Astrocitose difusa } \\
\text { acentuada }\end{array}$ \\
\hline & & & & & $\begin{array}{l}\text { Cerebelo, substância } \\
\text { branca subcortical }\end{array}$ & Edema acentuado \\
\hline
\end{tabular}

aFêmea, b macho.

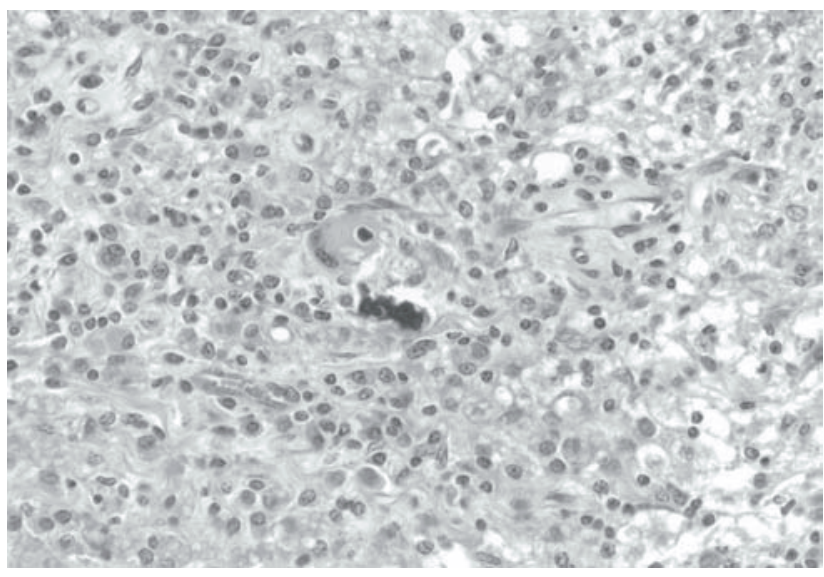

Fig.7. Acentuado infiltrado inflamatório granulomatoso no bulbo do Caprino $\mathrm{C}$ com listeriose. No centro observa-se uma célula gigante multinucleada e depósito de material amorfo basofílico (cálcio). HE, obj. 40 .

mocitários com células Gitter (Fig.6). No caso mais crônico (Caprino C) o infiltrado era composto de linfócitos, plasmócitos e macrófagos epitelióides, com formação de células gigantes multinucleadas (Fig.7). Além disso, no Caprino B, foi observado infiltrado linfocitário e neutrofílico no nervo trigêmio.

Na coloração de Brown \& Brenn as bactérias foram detectadas em grande número nos cortes de tronco encefálico do Caprino B (Fig.8), em pequeno número no Caprino A e estavam ausentes no Caprino C. Nas preparações de IHQ as bactérias foram encontradas no interior de neurônios (Fig.9) ou de células

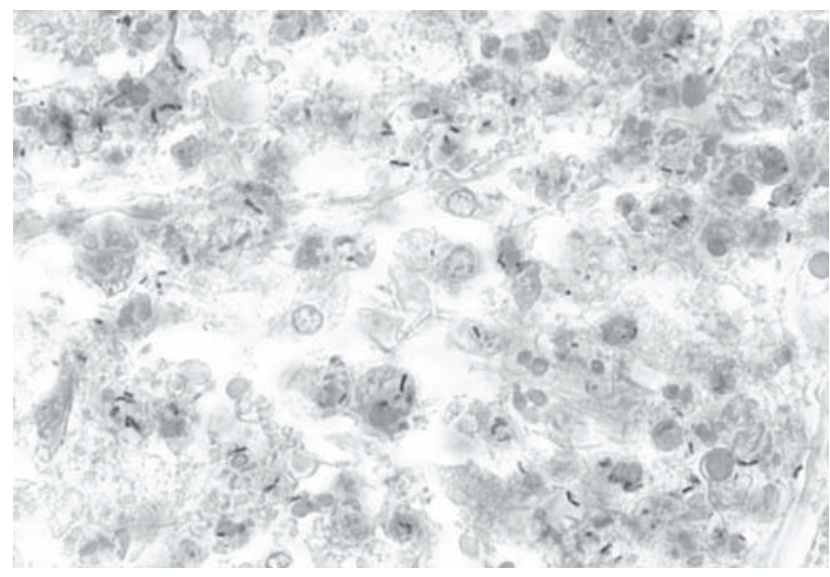

Fig.8. No interior de células inflamatórias do manguito perivascular, na ponte do Caprino B com listeriose, observam-se bactérias Grampositivas sob forma de bastonetes. Brown e Brenn, obj.100.

inflamatórias (Fig.10). Nessa técnica, as bactérias foram observadas em grande número no Caprino $\mathrm{B}$, em moderado número no Caprino A e em pequeno número no Caprino C. Os testes de PCR realizados em material fixado em formol e emblocado em parafina resultaram negativos para os três casos.

\section{DISCUSSÃO}

O diagnóstico de meningoencefalite por Listeria monocytogenes no presente relato foi baseado nos sinais clínicos, nos achados histopatológicos e na detecção do agente no tronco encefálico 


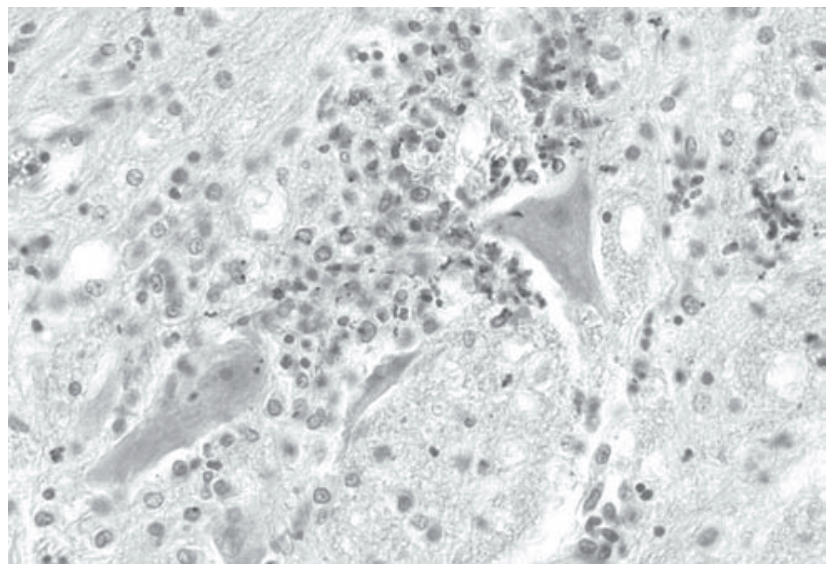

Fig.9. Bactérias no citoplasma de neurônios e de células inflamatórias coram-se positivamente (Caprino B com listeriose). Imunoistoquímica, Avidina-Biotina, obj.40.

por IHQ. A técnica de IHQ definiu a bactéria como membro do gênero Listeria. Embora existam suspeitas de reação cruzada do anticorpo entre espécies de Listeria (Ramos-Vara 2005), concluímos que o presente surto foi causado por $L$. monocytogenes, pois somente duas bactérias desse gênero causam doença em ruminantes (L. monocytogenes e L. ivanovii) (Schneider 1994) e apenas L. monocytogenes está relacionada a surtos de encefalite (L. ivanovii é associada somente à forma abortiva).

A IHQ tem sido usada com sucesso para a detecção de antígenos de $L$. monocytogenes em tecidos emblocados em parafina de casos naturais de listeriose em ovinos, caprinos, bovinos, camelídeos (lhamas) e aves (Peixoto 1986, Marco et al. 1988, Ramos et al. 1988, Johnson et al. 1995, Weinstock et al. 1995, Campero et al. 2002, Loeb 2004, Schwab et al. 2004). Em geral as bactérias são visualizadas nas áreas de microabscessos, no citoplasma de neutrófilos e macrófagos, mas também em neurônios normais ou degenerados. Situações onde a coloração por IHQ apresenta superioridade no diagnóstico da listeriose incluem (1) lesões com número reduzido de bactérias ou pouca quantidade de antígeno, (2) quando o material a ser testado é enviado já fixado em formol para o laboratório e (3) quando o cultivo ou a coloração de Gram resultam negativos (Campero et al. 2002, Loeb 2004). Isso ficou evidenciado neste trabalho. Em um caso (Caprino $\mathrm{C}$ ) onde não foi possível a visualização das bactérias, e em outro caso (Caprino A), no qual elas apareciam em pequeno número pela coloração de Brown \& Brenn, a técnica de IHQ demonstrou maior sensibilidade, revelando o agente em pequeno número e em número moderado, respectivamente. Num estudo retrospectivo, três métodos de diagnóstico para detectar $L$. monocytogenes em 42 cérebros de ruminantes (ovinos, caprinos e bovinos) com suspeita de meningoencefalite foram comparadas (Loeb 2004). A cultura bacteriológica foi positiva em $28,5 \%$ dos casos; a bactéria foi visualizada na coloração de Gram em 47,6\% dos casos e na IHQ em 80,9\% dos casos, o que indica que a IHQ é um método de diagnóstico mais sensível que o cultivo bacteriológico e coloração de Gram para o diagnóstico de listeriose. Além disso, o tempo de fixação em formol parece

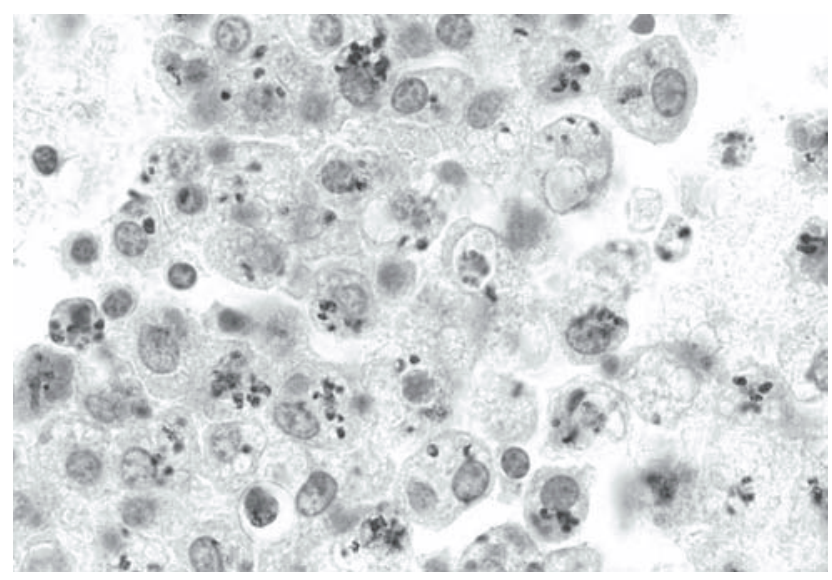

Fig.10. Bactérias no citoplasma de células Gitter coram-se positivamente, no mesmo manguito perivascular mostrado com coloração de HE na Fig. 6. (Caprino A com listeriose). Imunoistoquímica, Avidina-Biotina, obj.100.

não interferir na sensibilidade do teste, pois positividade tem sido encontrada em casos de tecidos fixados por 10 (Weinstock et al. 1995) e 17 anos (Campero et al. 2002).

Nos casos deste estudo, os microrganismos foram encontrados no citoplasma de células inflamatórias como macrófagos e neutrófilos e em neurônios. A reatividade fraca encontrada no Caprino C é explicada pela cronicidade da lesão, o que reforça a assertiva da sensibilidade do método imunoistoquímico, mesmo em casos onde há poucas bactérias. $\mathrm{O}$ teste de PCR resultou negativo para os três casos. Esses achados foram interpretados como falsos-negativos em razão do uso de formol não-tamponado como fixador e do tempo prolongado de fixação dos tecidos. Foi demonstrado (Ben-Ezra et al. 1991) que esses fatores prejudicam o teste de PCR e que resultados negativos têm sido obtidos em condições e tempo semelhantes de fixação.

O curso clínico e os achados histopatológicos do Caprino $\mathrm{C}$ são pouco comuns para casos de listeriose em pequenos ruminantes (Lippman 1969, Vandegraaff et al. 1981, Reuter et al. 1989, George 2002). No caprino C o curso foi bastante longo (30 dias), a lesão característica, com formação de microabscessos, estava ausente e havia uma reação inflamatória granulomatosa com células gigantes. A localização das alterações no tronco encefálico (bulbo, ponte e mesencéfalo) nos três casos deste estudo é consistente com o que é geralmente descrito para casos de listeriose encefálica em ruminantes (Charlton \& Garcia 1977, Jubb \& Huxtable 1993, Summers et al. 1995). Na listeriose, as lesões iniciam por focos de micróglia que, posteriormente, são infiltrados por neutrófilos e, mais tarde por células gitter (Charlton \& Garcia 1977, Vandegraaff et al. 1981, Summers et al. 1995, Storts 1998). À medida que a lesão evolui, os neutrófilos desaparecem (Storts 1998). Por isso, deve-se se ter cuidado em afastar um diagnóstico de listeriose simplesmente pela ausência de microbascessos ou de infiltrado neutrofílico nas preparações histológicas rotineiras. Lesões granulomatosas como as do Caprino C, no entanto, não são geralmente descritas em casos de encefalite por $L$. monocytogenes em ovinos e caprinos e, portanto, esse aspecto morfológico deve também ser levado em 
conta no diagnóstico da doença. A distribuição de lesões inflamatórias no tronco encefálico é um fator importante para conduzir à suspeita de listeriose em ruminantes. A localização preferencialmente assimétrica (unilateral) das lesões nestes e em outros casos de listeriose é também um aspecto a ser considerado no diagnóstico de rotina. Em muitos laboratórios no Brasil, o encéfalo é cortado sagitalmente na linha média e apenas metade é submetida em formol para histopatologia; isto reduz as chances de diagnóstico em casos de listeriose.

O curso clínico prolongado em casos de encefalite por $L$. monocytogenes, embora incomum não é inédito. Há um relato (Pillai 1962) em que um caprino afetado foi submetido à eutanásia 45 dias depois do início dos sinais clínicos. No Caprino $\mathrm{C}$ deste estudo, a doença talvez tenha sido prolongada pelo uso de antibióticos. Num surto de listeriose encefálica em caprinos no Iraque (Yousif et al. 1984) é concluído que a antibioticoterapia não tem sucesso na cura, mas prolonga o curso da doença.

Neurite com infiltrado neutrofilico e linfocitário intrafascicular e perineural em um ou mais nervos cranianos e no gânglio do nervo trigêmeo é um achado relativamente comum em casos de meningoencefalite por L. monocytogenes (Charlton \& Garcia 1977). A infecção do microorganismo no sistema nervoso central provavelmente segue uma rota neurógena ascendente (Campero et al. 2002), através do nervo trigêmeo (Asahi et al. 1957), facial (Borman et al. 1960) ou hipoglosso (Wesley 1999), secundariamente a abrasões na mucosa oral por alimentos fibrosos, erupção dentária ou lesões na mucosa nasal e conjuntiva (Charlton \& Garcia 1977, Otter \& Blakemore 1989, Wesley 1999). Evidências de invasão pelos nervos cranianos foram observadas no Caprino $\mathrm{B}$, que apresentava neurite do trigêmeo.

Freqüentemente os surtos de listeriose ocorrem no inverno ou início da primavera em animais alimentados com silagem (Charlton \& Garcia 1977, Vandegraaff et al. 1981, Barlow \& McGorum 1985, Wilesmith \& Gitter 1986). Entretanto, em casos de encefalite por $L$. monocytogenes em bovinos e ovinos no Rio Grande do Sul (Sanches et al. 2000, Schild 2001) esses dados epidemiológicos não têm sido constatados e a doença tem sido observada na primavera e verão em animais a campo. Condições semelhantes foram observadas em um surto de listeriose em ovinos no sul da Austrália (Reuter et al. 1989), onde os casos ocorreram entre janeiro e abril e raramente estavam associados à alimentação com silagem. Supõe-se que temperaturas moderadas, solos alcalinos, pastoreio em campos com pastos fibrosos, alterações de manejo, prenhez e altos índices de precipitação pluviométrica ou seca poderiam gerar condições favoráveis à manifestação da doença (Løken \& Grønstø 1982, Yousif et al. 1984, Johnson et al. 1996).

Nos casos aqui descritos, não foi possível determinar a fonte da infecção, mas galinhas, porcos e bovinos tinham contato com as cabras e poderiam ter sido a fonte de $L$. monocytogenes. As galinhas tinham inclusive acesso à mesma fonte de alimentação. Os caprinos deste relato tinham sido alimentados com silagem de milho, no inverno, há cerca de 4-5 meses. O período de incubação mínimo da listeriose encefálica é descrito como ao redor de 3 semanas (George 2002), mas pode chegar a 6-8 semanas (Vandergraaff et al. 1981). Se a silagem fornecida no inverno anterior aos caprinos fosse considerada como fonte da infec- ção, teria de ser considerado um período de incubação mais longo ou uma forma de latência que fosse ativada pelos fatores estressantes mencionados acima.

Surtos de meningoencefalite por $L$. monocytogenes em ruminantes são descritos com morbidade de 1\% (Vandegraaff et al. 1981) a 10 \% (Jubb \& Huxtable 1993), embora coeficientes de morbidade e mortalidade de respectivamente $30 \%$ e $21 \%$ tenham sido mencionados em surtos de encefalite e aborto em cabras no Iraque (Yousif et al. 1984). No surto daqui descrito, os coeficientes de morbidade e mortalidade foram de $3 \%$ e letalidade de $100 \%$.

Agradecimentos.- Os autores agradecem ao Dr. José Ramos-Vara, Animal Disease Diagnostic Laboratory, Purdue University, 406 South University, West Lafayette, IN 47907, Estados Unidos, pelo auxílio técnico na IHQ e pela revisão do manuscrito.

\section{REFERÊNCIAS}

Asahi O., Hosoda T. \& Akiyama Y. 1957. Studies on the mechanism of infection of the brain with Listeria monocytogenes. Am. J. Vet. Res. 18:147157.

Barlow R.M. \& McGorum B. 1985. Ovine listerial encephalitis: analysis, hypotesis and synthesis. Vet. Rec. 116:233-236.

Batt C.A. 1999. Rapid methods for detection of Listeria, p.261-278. In: Ryser E.T. \& Marth E.H. (ed.) Listeria, Listeriosis, and Food Saftey. 2nd ed. Marcel Dekker, New York. 738p.

Ben-Ezra J., Johnson D.A., Rossi J., Cook N. \& Wu A. 1991. Effect of fixation on the amplification of nuclei acids from paraffin-embedded material by polymerase chain reaction. J. Histochem. Cytochem. 39:351-354.

Borman G., Olson C. \& Segre D. 1960. The trigeminal and facial nerves as pathways for infection of sheep with Listeria monocytogenes. Am. J. Vet. Res. 21:993-1000.

Campero C.M., Odeón A.C., Cipolla A.L., Moore D.P., Poso M.A. \& Odriozola E. 2002. Demonstration of Listeria monocytogenes by immunohistochemistry in formalin-fixed brain tissues from natural cases of ovine and bovine encephalitis. J. Vet. Med. B 49:379-383.

Charlton K.M. \& Garcia M.M. 1977. Spontaneous listeric encephalitis and neuritis in sheep, light microscopic studies. Vet. Pathol. 14:297-313.

George L.W. 2002. Listeriosis, p. 946-949. In: Smith B.P. (ed.) Large Animal Internal Medicine. 3rd ed. Mosby, St. Louis. 1735p.

Johnson G.C., Fales W.H., Maddox C.W. \& Ramos-Vara J.A. 1995. Evaluation of laboratory tests for confirming the diagnosis of encephalitic listeriosis in ruminants. J. Vet. Diagn. Invest. 7:223-228.

Johnson G.C., Maddox C.W., Fales W.H., Wolff W.A., Randle R.F., Ramos J.A., Schwartz H., Heise K.M., Baetz A.L., Wesley I.V. \& Wagner D.E. 1996. Epidemiologic evaluation of encephalitic listeriosis in goats. J. Am. Vet. Med. Assoc. 208:1695-1699.

Jubb K.V.J. \& Huxtable C.R. 1993. The nervous system, p.267-530. In: Jubb K.V.J., Kennedy P.C. \& Palmer N. (ed.) Pathology of Domestic Animals. Vol.1. 4th ed. Academic Press, San Diego. 780p.

Lippman R. 1969. Clinical diagnostic and therapeutic studies on spontaneous nervous system listeriosis of sheep. Acta Vet. Sci. Hung. 19:161-169.

Loeb E. 2004. Encephalitic listeriosis in ruminants: Immunohistochemistry as a diagnostic tool. J. Vet. Med. A 51:453-455.

Løken T. \& Grønstø H. 1982. Clinical investigations in a goat herd with outbreaks of listeriosis. Acta Vet. Scand. 23:380-391.

Marco A., Ramos J.A., Dominguez L., Domingo M. \& Gonzalez L. 1988. Immunocytochemical detection of Listeria monocytogenes in tissue with the peroxidase-antiperoxidase technique. Vet. Pathol. 25:385-387.

Otter A. \& Blakemore W.F. 1989. Observation on the neural transport of 
Listeria monocytogenes in a mouse model. Neuropathol. Appl. Neurol. 15:590.

Peixoto P.V. 1986. Vergleichende histopathologische und immunhistologische Untersuchungen zur Diagnose spontaner Listeriose bei Tieren. Eine retrospektive Studie mit der Peroxidase-Antiperoxidase(PAP)-Technik an formalinfixierten Paraffinschnitten. Dissertation, JustusLiebig-Universität Giessen, Alemanha. 109p.

Pillai C.P. 1962. Listeriosis in a goat in the Sudan. Vet Rec. 74:15-17.

Ramos J.A., Domingo M., Dominguez L., Ferrer L. \& Marco A. 1988. Immunohistologic diagnosis of avian listeriosis. Avian Pathol. 17:227-233.

Ramos-Vara, J.A. 2005. Comunicação pessoal. (Animal Disease Diagnostic Laboratory, Purdue University, 406 South University, West Lafayette, IN 47907, Estados Unidos).

Ramos-Vara, J.A. \& Beissenherz M.E. 2000. Optimization of immunohistochemical methods using two different antigen retrieval methods on formalin-fixed, paraffin-embedded tissues: experience with 63 markers. J. Vet. Diagn. Invest. 12:307-311.

Reuter R., Bowden M. \& Palmer M. 1989. Ovine listeriosis in south coastal Western Australia. Aust. Vet. J. 66:223-224.

Sanches A.W.D., Langohr I.M., Stigger A.L. \& Barros C.S.L. 2000. Doenças do sistema nervoso central em bovinos no sul do Brasil. Pesq. Vet. Bras. 20:113-118.

Schild A.L. 2001. Listeriose, p.288-292. In: Riet-Correa F., Schild A.L., Méndez M.C. \& Lemos R.A.A. (ed.) Doenças de Ruminantes e Eqüinos. Vol.1. Varela, São Paulo. 425p.
Schneider D.J. 1994. Listeriosis, p.1374-1377. In: Coetzer J.A.W., Thomson G.R. \& Tustin R.C. (ed.) Infectious Diseases of Livestock with special reference to Southern Africa. Vol.2. Oxford University Press, Cape Town. $1605 p$.

Schwab J.P., Edelweiss M.I.A. \& Graça D.L. 2004. Identificação de Listeria monocytogenes pela técnica de imunohistoquímica em tecido nervoso central de ruminantes. Revta Portuguesa. Ciênc. Vet. 99:65-66.

Storts R.W. 1998. Sistema nervoso central, p.353-416. In: Carlton W.W. \& McGavin M.D. (ed.) Patologia Veterinária Especial de Thomson. ArtMed, Porto Alegre. 672p.

Summers B.A., Cummings J.F. \& de Lahunta A. 1995. Listeriosis, p.133135. In: Ibid. (ed.) Veterinary Neuropathology. Mosby, Baltimore. $527 \mathrm{p}$.

Vandegraaff R., Borland N.A. \& Browning J.W. 1981. An outbreak of listerial meningo-encephalitis in sheep. Aust. Vet. J. 57:94-96.

Weinstock D., Horton S.B. \& Rowland P.H. 1995: Rapid diagnosis o Listeria monocytogenes by immunohistochemistry in formalin-fixed brain tissue. Vet. Pathol. 32:193-195.

Wesley I.V. 1999. Listeriosis in animals, p.39-73. In: Ryser E.T. \& Marth E.H. (ed.) Listeria, Listeriosis, and Food Safety. 2nd ed. Marcel Dekker, New York. 738p.

Wilesmith J.W. \& Gitter M. 1986. Epidemiology of ovine listeriosis in Great Britain. Vet. Rec. 119:467-470.

Yousif Y.A., Joshi B.P. \& Ali H.A. 1984: Ovine and caprine listeric encephalitis in Iraq. Trop. Anim. Hlth Prod. 16:27-28. 